\title{
The Reflective Study on Dropouts of Professional Golf Trainees
}

\author{
Hyuck Ki Lee ${ }^{1}$ \\ ${ }^{1}$ Professor, Department of Sports\&Sports Instruction, Daekyeung University, Korea, \\ national01@ hanmail.net
}

\begin{abstract}
The present study is aimed at investigating the reflections of golf trainees who dropped before becoming professional golfers. In this study, five former golf trainees were recruited to be interviewed and the researcher conducted three-rounds of in-depth interviews. Collected data were transcribed and analyzed by the researcher, and content analysis was conducted. Research findings indicate that the former golf trainees showed three distinctive features: 1) psychological problems, including metal problems, relationship with parents and the identity, 2) physical problems, which are caused by injuries while practicing and playing, and 3) economic problems, which are related to the financial status of parents and scholarship or sponsorship. In addition, participants were asked about their plans after dropping-out. They responded that they planned to study in sports or other fields of the study as a student. However, the former golf trainees expressed difficulties going back to the regular schooling system, because they had spent most of their school life at golf courses rather than in the classroom. In sum, the present study proposes systematic changes for the dropout of golf trainees who spend most of their adolescent years at golf courses. It is critical to grow more concern on schooling of these students.
\end{abstract}

Keywords: Professional Golf Trainee, In-depth Interviews, Content Analysis, Schooling System

\section{Introduction}

With the rising income level and the generalization of the five-day work a week, interest in health is spontaneously increasing. With the advent of Tiger Woods in the 1990s, a worldwide revival of golf began and many young teenagers started playing golf to become famous players like Tiger Woods. Along with general interest in golf, the performance of Korean players in major golf leagues has promoted the interest in golf in Korea. In addition, Se-ri Pak, famous for her barefoot fighting spirit, led to the emergence of new golf trainees called "Se-ri kids" in Korea after her victory in the US Open in 1998. Since that, many golf trainees are striving to practice for their future at the golf practice range. However, it is very difficult to become a professional golf player, and in the case of Korea, the qualification of associate members (semi-professional) and regular members are requested only after passing the professional selection tournament held by the association regulations of the Korea Professional Golf Association (KPGA) or the Korean Women's Professional Golf Association (KLPGA)[1] and [2]. According to the rules of Golf Association, a total of three times a year for the Associate Membership Qualification Tournament (MQT) is held in each region for 36 holes, with 240 people participating in the central final. They play 36 holes again, and 100 players are selected to be qualified as associate members. In addition, only those with associate membership players are qualified as regular members and tour pros through 36 holes in each region and 72 holes in the final tournament[3]. In the case of KLPGA, the process of selecting associate members and selecting regular members is conducted by

Received: August 25, 2020; $1^{\text {st }}$ Review Result: October 12, 2020; $2^{\text {nd }}$ Review Result: November 30, 2020 Accepted: December 28, 2020 
adopting a similar method to that of KPGA[4]. In this way, becoming a professional golf player can only be obtained by overcoming difficult environmental factors and surpassing numerous competitors. Currently, there is no accurate number of inquirers who are training to become professional golf players in Korea, but as of 2019, only 1,763 players registered in the KJGA[5]. The number of athletes registered in KCGF[6] is about 1,000, and it can be said that the number of athletes registered in these two organizations alone is dozens of times the number of players who are given professional qualifications during the year[1]. In addition, the number of those who wish to practice to become a professional golf player are joining a golf academy, a golf practice range, or golf courses without affiliated organizations. However, it is also recognized that the number of golf trainees who give up in the middle of training is increasing as the number of golf trainees increases. The research on the accurate estimation of the number of trainees and the reason for their giving-up, and the countermeasures after giving-up golf is insufficiently found in the studies of golf. According to [7], the athletes are experiencing mental and physical stress while performing sports and they are less interested in sports, which leads them to givingup exercise. [8] stated that stress affects the persistence of exercise in playing golf and it has a significant effect on giving-up to play golf. Factors for stopping, giving-up, or withdrawing from the sports exercise is elucidated by studies on dissatisfaction or skepticism about achievement results, career issues, problems with leaders, discord about achievement results, career issues, problems with leaders, uncertainty in the future, discord in interpersonal relationships, and loss of motivation[9]. [10] mentioned the phenomenon of many professional golf players quitting golf due to psychological difficulties in performing the game. [11] pointed out that only a small number of players can survive through the slump of professional golf players and struggled with ways to overcome this problem. [7] conducted a study to investigate the causes of dance sports' players giving up during exercise and showed that psychological factors play a critical role in the dropout rate. However, there is rare research on the abandonment of sports of golf trainees. Thus, the present study is aimed at investigating the causes of golf trainees giving-up on sports and suggests solutions for student-golf trainees. The research questions used to guide the study include:

1) What are the main reasons why golf trainees give up exercise?

2) What is the plan for aspiring golf players after giving up exercise?

\section{Research Methods}

\subsection{Participants}

The present study is aimed at investigating students enrolled in university and affiliated with the golf academy, having a professional golf trainee experience. Five college students in their twenties who have given up golf and are currently majoring in sports or other fields were selected as the participants of the study. To collect the data, three in-depth interviews were held for three months from June to September 2019. The participants of this study consisted of male students $(n=4)$ and female students $(n=1)$ respectively, and all were in their twenties (between 22 and 27 years old). They had 8 to 12 years of athletic experience. The period of giving-up exercise was reported as 2 to 7 years. It was found that most of the participants spent their teenage years as golf trainees and gave up athletic training in their early twenties. Table 1 shows detailed information of demographical characteristics of participants.

[Table 1] Demographical Characteristics of Participants

\begin{tabular}{|c|c|c|c|c|c|c|}
\hline Participants & Gender & Age & $\begin{array}{c}\text { Career of } \\
\text { exercising }\end{array}$ & $\begin{array}{c}\text { Age to start } \\
\text { exercising }\end{array}$ & $\begin{array}{c}\text { Age to stop } \\
\text { exercising }\end{array}$ & Status \\
\hline A & M & 22 & 10 & 10 & 2 & College student \\
\hline B & M & 26 & 12 & 11 & 3 & College student \\
\hline
\end{tabular}




\begin{tabular}{|c|c|c|c|c|c|c|}
\hline C & M & 24 & 8 & 13 & 2.5 & College student \\
\hline D & M & 25 & 8 & 15 & 2 & College student \\
\hline E & F & 27 & 10 & 10 & 7 & College student \\
\hline
\end{tabular}

\subsection{Data Collection and Analysis}

Three in-depth interviews were conducted by determining the availability of each participant, and each interview was conducted for 1 to 2 hours in the researcher's laboratory. The structural questions used in the interview are as follows.

1) What was your daily routine while playing golf, and with whom and where did you live?

2) What are the main factors why you quit playing golf?

3) What changed in your life after giving up golf, and what are your future plans?

Structured interviews were mainly conducted centering on three questions, and semi-structured interviews were also conducted depending on interviewees' responses. The interviews were recorded with the consent of the interviewee, and detailed notes were taken by the researcher. After the interview, the recorded content was immediately transcribed, and in this process, any content words uncleared or misunderstood were confirmed through the interviewee. Since the interview questions are highly related to interviewees' privacy, it was conducted under the ethical agreement between the researcher and interviewees and 10 points of ethical consideration were informed to each interviewee.

- Research participants should not be subjected to harm in any ways whatsoever.

- Respect for the dignity of research participants should be prioritized.

- Full consent should be obtained from the participants prior to the study.

- The protection of the privacy of research participants has to be ensured.

- Adequate level of confidentiality of the research data should be ensured.

- Anonymity of individuals and organizations participating in the research has to be ensured.

- Any deception or exaggeration about the aims and objectives of the research must be avoided.

- Affiliations in any form, sources of funding, as well as any possible conflicts of interests have to be declared.

- Any type of communication in relation to the research should be done with honesty and transparency.

- Any type of misleading information, as well as representation of primary data findings in a biased way must be avoided.

The collected data are analyzed based on the phenomenological analysis method of [12], which allows exploring the essential meanings obtained from experiences, and what the interviewees feel in the present state after giving-up the sports and the experiences of those who gave up on professional golf. In addition, in qualitative research, analysis and interpretation of the collected data along with the collection of data is as important as the collection of data[13]. Therefore, in this study, the two-step method of domain analysis and taxonomic analysis developed by [14] was applied to the analysis process. In the domain analysis, while continuing to peruse the interview records, the study searched for empirical and meaningful contents in the data, identified words that best represent the contents, and determined the domain[15]. In the systematic analysis, the collected interview data are systematically classified, and the subjects of the intermediate classification including the key words derived through the domain analysis are found, and the main subject that encompasses it is found again.

\subsection{Securing the Validity of the Data}

Peer debriefing was used to secure the validity of the data collected through in-depth interviews with 
golf trainees. To this end, the analysis of the interview was shared with two full-time faculty members in the same department as this researcher. In addition, since the researcher has been teaching golf trainees for many years, the method of progressive subjectivity was used to exclude prejudice toward the interviewees participating in the research as much as possible, and to prevent the subjectivity of the researcher from intervening. Through this, the space for distorting or misunderstanding the facts based on the differences or perspectives of individual interviewees was reduced[16]. In addition, the interpretation of the collected interview data was checked by the interviewees once more in order to confirm that the inference and interpretation of the meaning coincided with the interviewees' response intention.

\section{Findings and Discussion}

\subsection{Reasons for Dropout of Golf}

Golf trainees' give-up golf was explained by individual reasons, which are classified by physical, psychological and economic problems. Physical problems are also divided into factors caused by injury, psychological problems which are further divided into mental problems during practice and stress on protests, changes in relations with parents due to long exercise sessions, and the problems with investment costs are found.

\subsubsection{Psychological Problem}

\subsubsection{Mental Problems}

Abandonment of exercise due to psychological factors was the highest cause, and identity, burden of game, and conflict with parents were found to be major issues. People who started sports to become professional golf players are called "trainees," and due to the nature of the sport of golf, show a different daily life than general student players. Most of the trainees, which included middle and high school students as well as pro aspirants, were students and both groups had the status of trainees, expressing confusion about their identity. One example is described as follows.

"The ball hits too well in the practice field or practice rounds. It's like hitting the ball the way I want. It's not my pride. I was able to do the same shots of famous players on TV. When I went to the players' game, I felt like I was hitting straight further. It was fun to hit the ball. But, if I only went out in a match, I was too nervous. I went to the practice round and hit the under par, but it came in, I hit over 10 and fell in the qualifier. Oh, it was really crazy. I even went to the mental coach and asked for a consultation. I'm not a professional player, but I was so nervous when I went into a play strangely. I also make a lot of mistakes in putting (Interviewee C).

"After the game, I was so nervous in the first hall. When I practice, I hang out with my friends or my close people, so I play with a pleasure. Strangely, in a match, if that short putt falls out, it doesn't leave my head until the end of the match. So I keep making mistakes. In competitions and pro tests (QSchool), I get stuck with one stroke and fall. It didn't work out my way (Interviewee D).

It was found that if the participants showed superior skills in the practice field or the practice round, and could not overcome it due to excessive tension or pressure in the actual game, the golf aspirant was extremely anxious and could not demonstrate their ability. Therefore, in order to overcome these mental problems, it is judged that not only individual players, but also parents and leaders all need to seek new ways. In addition, among the interviewees in this study, B, who was judged to be the best in golf technique, had difficulties in terms of mentality.

"I've heard a lot of stories around me since I was a kid because I'm really good at ball. So, of course, becoming a national representative and becoming a professional player was just a matter of course. 
Then, after finishing first in the preliminary round in the pro test, I entered the finals and hit too much on the first day. Strangely, I couldn't hit the ball as if I was possessed by something. I hit well on the second day of the finals, but I fell because I couldn't make up for the number of at-bats I lost on the first day. Then from then on, I couldn't just go out for the pro test. And it happened that I ruined the game every day and ruined it all over again (Interviewer B).”

"I've heard a lot of stories that I practice a lot. The driving range boss always told me that I was the last person to go home, and that you will definitely succeed. I neither thought I would not lose the amount of practice to anyone, but I have a friend who started playing golf, and he has become a famous player on TV now. I'm not even a professional yet. When I got the friend's tour card, I was offended a lot while calling congratulations. Until now, all the time spent practicing was regrettable. So, from some point, I was practicing vaguely. Even if I think about it myself, it seems like I was just in the practice field without meaning (Interviewer A)."

Due to the nature of the sport, golf is a sport that is greatly influenced by the condition and natural environment of the day. Therefore, aspiring athletes must quickly recognize that there are many external variables due to the nature of the sport, and develop measures and capabilities to overcome them. It is assumed that it is natural for all exercises to achieve the results in proportion to the amount of exercise [17] and [18]. However, golf is regarded as a representative sport among events whose results are not always proportional to the amount of practice. Under these circumstances, while preparing for a competition, the mental stress that the athletes who perform the exercise face are even greater.

\subsubsection{Relationship with Parents}

Golf is one of the sports that actively require parental help due to the nature of the sport. In particular, for children who are minors, parents avoid moving to a far-off golf course, and do not hesitate to wait at the golf course until the game is over.

"Once, there was a game at a golf course in Gunsan. Since the game usually starts on Thursday, I left for Gunsan with my mom on Tuesday at dawn, and I did a good practice round but ruined the game. After submitting the scorecard, I felt depressed, but I found my mom was angry. I got upset as well. Then I didn't say a word until I got home. We'd been driving for 4 hours and I didn't say a word for a few days. Of course I knew it was because of my fault, but I didn't say I was sorry. Mom didn't say anything at all (Interviewer E)."

"I still remember that day. I played the first half well and came in. As I went out of the course after the clubhouse, I showed my dad a fist to say that I was confident and went out to the course, but in the second half, I wasn't very good at it. I also got 3 OBs (Out of Bounds). After the game, my father ran first, and when he looked at my face, he asked me why. I said I wasn't good, I submitted my scorecard, and he said he would wash it out, but he slapped me on the cheek (Interviewer D)."

From the parental point of view, it was found that when children who trust and support more than anyone else have negative results, they felt a sense of betrayal and frustration. Due to this, the unsatisfactory relationship between children and parents is observed, and as a result, golf trainees have a negative effect on the development of their skills and show the failures on the tests. Golf trainees have no professional coach or manager and most parents do their roles as a coach and managers at first. Therefore, the relationship between parent and child is developed not as a coach and trainee but as a child and parents[7]. As most trainees are in the period of puberty, they need more attention from their parents than any other stage of child development and have developed somewhat of a strange relationship. Also, parents' high state of expectancy makes them more nervous and anxious.

\subsubsection{Identity}

To become a professional golf player, it is necessary that every golf trainee has to go through a series 
of tournaments called Q-School. The qualifications of a professional golfer are sometimes granted by some associations such as the Korea Middle School Golf Federation, Korea University Golf Federation, Second Level Tour, Challenge Tour, KPGA Academy Tour, etc. Thus, it is necessary for students who started sports to become professional golf players through "trainee" programs. They are encouraged to join several associations and have a different life style from general student players due to the nature of the sport of golf.

"When I go to another driving range or golf course to practice, there are a lot of people who see me hitting the ball and ask if I'm a pro. Once I practice at the practice range, the pro went outside to meet me to ask who I am. So I decided to just practice and bet drinks with the kids of the same academy. But some days like holidays, I go to the practice range and play with regular customers. But one person came and said, 'let's practice quietly for the trainees.' I thought, 'Will the trainee do that and become a pro? Anyway, if I only came out of school, I was a trainee." (Interviewer C).

"There are rare golf driving ranges or golf courses near my schools. When I started playing golf at the age of 10, I had to spend most of my time in a driving range rather than school. The schools I attended didn't have an athletic department and a golf department. My parents talked to the teacher. Now that I have to play golf, I ask for the convenience of the class. I can't go to the golf course with a golf club alone. My parents always took me to the practice field where the pros were. The first word I heard there was 'You're a new trainee!'” (Interviewer A).

"I played golf at the academy, 1 or 2 rounds every week. When I go there, the counter told me the time I leave and I would say I am a student, at the golf academy everybody called me as a trainee not a student or a player. I think those of me who play golf are called trainees. But when I asked my athletic friends at school, they were called athletes" (Interviewer D).

It can be seen that the lives of prospective professional golf players are not much different from those of interviewees. For them, the school was recognized as a place to come after a short break, and there were no special measures for class deficits because there was not an athletic department and teachers. It is important for student-athletes to learn at school and their right should be guaranteed[19]. However, in the case of golf trainees, the reality is that they are classified as having their own choice and no request can be made.

\subsubsection{Physical Problems}

In this study, Interviewer B had experience winning various competitions with considerable skill in his middle and high school. He's even lived in a backup national athlete of golf, but due to injuries to his hand, he underwent several surgeries and gave up golf.

"I couldn't do that anymore. No matter what, I can't do anything. There seemed to be no one playing better than me at the practice range. Whenever I went out in any game, I was always in the top ranks, but then, I went to the hospital because the back of my hand hurts so much that I have to undergo surgery. Oh, I'm really hitting the ball for a long time, but I wondered why this happened to me. I haven't been able to play for 7 months after surgery. Then, as I grabbed it again, I felt like I was doing it all over again. Then I operated on the back of the hand three more times. The back of my hand was functioning, but I had another problem with my knee at that time, so I had surgery. There was no way" (Interviewer B).

"When I hit the ball at the practice range, I would come up downstairs and look at myself. I hit the ball while adjusting all of the fades and draws. Even if I think about it, I was really good at the practice range. But one day, my back hurt so much. I didn't think I had done anything. I went to hospitals, rehabilitation centers, and oriental clinics with my dad and mom. But I had to quit because I was so sick. I was so upset because I had confidence to do really well. (Interviewer E).

Most of the study participants have experienced injuries like B and E, and golf, like other sports, has 
a significant risk of injury too. Due to this, there are cases of giving up exercise, so it can be said that preventive care for trainees is important.

\subsubsection{Economic Problem}

Golf is an exercise that requires a lot of financial costs in comparison to other sports. It requires payment for the equipment used, the cost of professional lessons, the cost of using the golf course, the cost of moving for a game, and the cost of lodging.

"I have played golf for 10 years and had a chance to talk with my father one day. He said that it has cost 1 billion won since the 3 rd grade of elementary school. At first, I thought he was lying, but I thought that it would cost that much after calculating. I was very surprised. I spent that much money, but I'm still not a professional, and I have to keep spending money." (Interviewer A).

"When I was in elementary school, I used to live in a really big house, and I thought I just lived without any worries. When I was on vacation, he always allowed me to go abroad. He paid for golf clubs and anything I wanted to do. Then, my dad told me that the business wasn't going well. Even so, he actively supported me in golf. Then, I consulted with a professional with my father, and he said that if I didn't do it this year, I would stop playing golf. He said it was difficult because the cost was too high. I was disappointed at that time, but now I understand everything." (Interviewer C).

Likewise, the golf trainees are very sensitive to the cost of playing golf, which can be regarded as the same for their parents. The economic situation is a challenge for every case, and it's difficult to find student grants or sponsors for trainees.

\subsection{Plans after Giving up on Golf}

Golf trainees had considerable difficulties even after returning as general students due to the vacancy of their school days and the disconnected life from society. In this study, interviewers found that no one had properly performed regular school classes when starting golf. They were not allowed not to attend classes in the name of specialty students, golf trainees. When they gave up golf, they had to go back to school and start life as a general student. But a considerable period of adaptation was required.

\subsubsection{Continuing Sports Major}

The golf trainees who quit playing golf in this study were in their early twenties and most of them want to back to school. Among them, although they quit golf, there are students who are still interested in the sports major.

"When I first quit playing golf and thought I had to study. Since I was in elementary school, I usually missed the classes because I was playing golf. When I went to school, it seemed like I was speaking an alien language. If I knew I quit playing golf, I would have done some studying. I have a lot of regrets. It is frustrating, but since I was young, I have been playing golf and have seen a lot of sports, so I decided to enter college to study sports. I thought that I wanted to study sports, but I realized that there are so many different parts of sports. Among them, there are people I saw every time I participated in the tournament, and I knew that they were not affiliated with golf courses, but sports event companies. So I wanted to study in that field. Of course, it seemed difficult for them to work. However, I was always attracted to playing tournaments on the golf course and helping players to show their best skills. Just as I dreamed of becoming a player while stepping on the grass of a golf course, I wanted to try running and managing the golf tournament like this unless I was a player." (Interviewer B).

"Also, my physical strength seemed to be weaker when I was playing golf, so I started other sports. I've wanted to learn to swim. My friends who play golf don't have a lot of friends who do other sports. If you get injured, you can have trouble playing golf. As I learned to swim at dawn, the issues I struggled 
with while playing golf improved a lot. I'm also preparing to get a swimming license. I don't want to specialize in swimming, but I am aiming to because I have a license. When I was playing golf, I had a chance to teach someone, and it was a lot of fun. I heard a lot of comments from my ex-students that it's easy for them to understand golf. So, I think it would be nice to be a teacher in sports. There are quite a lot of things to learn to swim to become an instructor. But I have a specialty to practice any sports. I analyze the video of swimming like golf. In addition, I felt a lot of pressure when playing golf, but when I swim, I just enjoy it. When I'm in the water, I feel comfortable." (Interviewer E)

\subsubsection{Joining Other Majors}

Among the interviewees, some former golf trainees showed a negative attitude toward the sports including golf and decided to continue studying majors that are not related to sports. According to [1], after dropout the sports player, most of trainees are attempting to start the new life because the major reason to quit the sport is related to the stress and psychological problems. In this study, as shown in the interview about the reason for dropout, most of responses are related to their psychological problem, mental problem, identity-related problem and conflict with parents. As going after their natural defense mechanism to try to escape from the similar sports situation, former golf trainees are trying to start the new career or schooling in college. Also, they're still in twenties, even though their studying habits are not settled up, it's easy to find them in college, studying sports-not-related majors. However, in case of interviewer E mentioned, a former trainee majored in sport-not-related studies, but related to their experience in training.

"I only played golf. I went to school only in the morning. I went straight to the practice range after school. I quit playing golf but couldn't go back to school right away, and I had to think about my future. Before playing golf, when I was young, I wanted to become a kindergarten teacher. The children are so pretty. Children follow me well. So, I wanted to become a kindergarten teacher, so I entered college to study early childhood education. It was not easy and the school was busier than I thought. I sometimes think about what would have happened if I didn't know golf in the first place. Now I'm satisfied with my performance." (Interviewer C)

"I had frequent injuries while playing golf, and because of this experience, I decided to study in the field of exercise rehabilitation or physical therapy. Of course, it's difficult, but if there are people who are hurt by golf, I can share the feeling of injuries with others. This study is not easy for learning. I had to memorize a lot of body parts such as muscle structure, names of muscles, the structure of the skeletal system and many other difficult terms. By the way, I got injured in those parts so I know how to be recovered by reducing pains. I love learning these things. In particular, when I was taking classes on golf-related injuries, each situation was my situation. So, I was more immersed in my studies, and while practicing various pain relief therapies, it is very fun. I quit playing golf and felt depressed for a while, but my parents were very satisfied with the way I was studying hard in this department. When I quit playing golf and became depressed, I was worried a lot. I was always thinking that I had to become a player, but now I have the confidence that I can do it and do better in other fields, it is just the past that I struggled with golf. It didn't matter whether it was good or bad." (Interviewer E)

"I thought I wasn't going to quit playing golf, and I didn't know what can I do without golf. One of my father's friend is running a business, and he told me that come to his office and learn to work. So, I started working for about a month. I thought I could do pretty well. However, it turns out that working in business was very different from working for a golf. For a few days after work, I felt pain in whole body. After working for a week, I started to adjust little by little. Even though I still feel pain in body, I don't think I want to play golf again. It was so amazing. Since I was young, I only played golf with the intention of becoming a professional golfer like Tiger Woods. After working for about three weeks, I suddenly thought that even if I do business like this, there would be limits to what I could do only with 
physical labor. At that time, I was able to watch the stories of successful people by choosing a new path while quiting elite sports on TV. What they had in common was that they quit exercising and started studying. Since that, I thought I had to study to do something new. I don't know what to study, but I wanted to make a lot of money. I went to the bookstore and bought some of the easiest books on economics and management and there were full of fun. I told my parents that I wanted to go to college and study economics and business administration. Again, my parents supported me. That's how I became a college student now." (Interviewer D)

\subsection{Discussions}

In the findings, participants in this study elucidated the reasons for dropout are their psychological, physical and economic problems. They are intertwined with intrinsic and extrinsic factors of players. In the previous studies like [7],[8] and [10], professional sports players' dropout reasons are strongly related to their psychological problems such as loss of motivation, slump and high anxiety on professional games or matches, while this study found that student players or trainees showed more reasons related to economic problems. As student players or a golf trainee, they have rare changes to $s$ to find sponsors or guardians, thus parents' economic supports are highly regarded for them to become a professional golf player. During the training period, most of golf trainees are starting to play golf with their parents' suggestions or encouragement at the beginning. Parents are playing multiple roles as a sponsor, coach and manager or scheduler. Thus, the study suggests that the relationship between parents and trainee is the key factor for them to become professional players. The findings are also supported by leisure constraints theory that human behavior is complex and influenced by immediate and more distal environment, thus they inhibit and prohibit participation in leisure activities such as sports participation. The dropout reasons for golf trainees are also explained by one of leisure constraints. In addition, the present study conducted the interview to ask about the plan after giving up golf and found that all golf trainees want to continue their schooling in college. Although they showed the different demand for the field of studies, college degree is considered as the principal requisites for their future.

\section{Conclusion}

The researcher has had many years of experience in nurturing golf trainees and professional players. The present study was conducted on the experience of maladjusted behavior of formal golf trainees at school. The study attempted to grasp the structure of the problem of abandonment of sports among golf trainees, who are relatively out of the classification of student players. Throughout their lives, they believe the meaning of golf, that is, exercise in their lives. The study collected the primary data through long-term observation and individual interviews with golf trainees. They reported problems such as injuries while playing and practicing, confusion about the identity as a golf trainee, and other psychological problems and stress on testing to become a professional[20]. In addition, the conflict with parents and economic problems led them to a decline in playing golf. The findings in this study are similar to those found by [20] and [18]. The difficulty of declining skills and psychological, physical, and economic factors are the reasons for student players to give up exercise halfway. In the systematic review of dropout from organized sport among children and youth[21], many discrete factors related to dropout were identified and they are lack of enjoyment, perception of competence, social pressures, competing priorities and physical factors. Even at this moment, many young players are striving to become the second KJ Choi or Se-Ri Pak and spend their youth at the driving range and golf course. Therefore, it is suggested for golf trainees to become a professional player within an appropriate period of time if possible, and prevent excessive absence of school classes. They need to develop a wide range of choices that can be made when choosing a career in the future. These are some limitations of this 
study; first, this study was conducted as a qualitative study, so the results of the study cannot be quantified in numbers. Therefore, a quantitative study is needed to collect and quantify the data of golf trainees who did not obtain the qualifications of professional athletes who have stopped exercising. Second, since the researcher has been instructing athletes for many years and has had experience as a golf trainee, it was helpful in understanding their language and culture, but the results cannot be generalized and there may be some stereotypes. Thus, the study proposes that further research on golf trainees will be conducted from a newer perspective in the future.

\section{References}

[1] M. G. Seok. The Plan of Korea College Golf Federation for Revitalization, Graduate School of Kyung Hee University, Unpublished, (2014)

[2] https://kusf.or.kr/, Korea University Sport Federation, Jun 25 (2019)

[3] http://www.kpga.co.kr/Association/openSelection.kpga, Jun 25 (2019)

[4] https://klpga.co.kr/web/tour/tourList.do?dcode=TE\&flag=1, KLPGA, Jun 25 (2019)

[5] http:// kjga.or.kr/n_Public/index.asp, Korea Junior Golf Association, Oct 21 (2019)

[6] http:// http://www.kcgf.org/html/main/index.php, Korea College Golf Federation, Nov 11 (2019)

[7] C. S. Lee, K. W. Kim, Sources of Stress in Junior Elite Boxers, Korean Society of Sport Psychology, (2011), Vol.22, No.1, pp.231-242.

[8] D. S. Chang, When the athletes want to give up the sports? Sports Science at a Crossroad of Transition: Challenges and Opportunities, (2011), June 15-19; Seoul, Korea

[9] B. J. Song, C. W. Lee, T. J. Chon, The conflict and deteriorating competence of former national golf team player from the before and after turning to professional, Korean Alliance for Health, Physical Education, Recreation and Dance, (2007), Vol.46, No.3, pp.313-323.

[10] Y. S. Lee. Analysis on the cause and overcome of slump for professional tour golfer, Graduate School of YonSei University, Unpublished, (2005)

[11] W. S. Myung, Y. L. Choi, Legal and pedagogical study on the policy for student-athletes' right for learning: A case of rule in Korean collegiate sport, Korean Journal of Sport Science, (2019), Vol.30, pp.345-359.

[12] J. W. Creswell, C. N. Poth, Qualitative Inquiry and Research Design: Choosing among Five Approaches, 3rd, SAGE Publications, (2015)

[13] T. H. Ryu, Life history approach to career identity development in a physical education teacher, Graduate School of Seoul National University, Unpublished, (2000)

[14] J. P. Spradley, The Ethnographic Interview, Holt Rinehart and Winston, (1979)

[15] D. K. Park, H. K. Park, J. W. Jeon, Exploration of Dropping Out Factors Appearing in Primary School Table-tennis Player's Entrance Process into Middle School, Korean Society of Sport and Leisure Studies, (2016), Vol.64, pp.579590.

[16] N. K. Denzin, The research act: A theoretical introduction to sociological method, McGraw-Hill, (1978)

[17] J. A. Kim, Humanities and Social Sciences: Exploratory Research on Why Dancesport Athletes Renounce Halfway, The Journal of Korean Dance, (2012), Vol.30, No.1, pp.217-252.

[18] K. Y. Lee, The Effect of Sport Injury on Sport Stress, Social Support, and Coping Skill of Athletes, Korean Society of Sport Psychology, (2002), Vol.13, No.3, pp.141-155, DOI: JANTVol.13(No.3) 141-155, 2002.

[19] S. L. Yoo, J. G. Park, H. J. Um, A Case Study on Student-athletes' Adaptation to School Life in Elementary School 
Based on the Theory of Self-resilience, The Korean Journal of Elementary Physical Education, (2012), Vol.18, No.2, pp.15-26.

[20] B. K. Pyon, On the relationship between stress and mental health of college students and mediating effects of social support, Asia-pacific Journal of Convergent Research Interchange, (2017), Vol.3, No.4, pp.43-56.

[21] J. Crane, V. Temple, A Systematic Review of Dropout from Organized Sport among Children and Youth, European Physical Education Review, (2014), Vol.21, No.1, pp.114-131. 